\title{
EFEITOS DA PANDEMIA DE COVID-19 SOBRE A SUSTENTABILIDADE ECONÔMICO- FINANCEIRA DE EMPRESAS BRASILEIRAS
}

\author{
EFFECTS OF THE COVID-19 PANDEMIC ON FINANCIAL SUSTAINABILITY OF BRAZILIAN \\ COMPANIES
}

\author{
EWERTON ALEX AVELAR \\ Doutor em Administração \\ Universidade Federal de Minas Gerais - UFMG \\ Orcid: https://orcid.org/0000-0003-2374-8954 / E-mail: ewertonalexavelar@gmail.com \\ Avenida Presidente Antônio Carlos, no 6627, sala 2031 - Pampulha - Belo Horizonte - MG, CEP: \\ 31270-901

\section{PRISCILA OLIVEIRA FERREIRA} \\ Graduada em Ciências Contábeis - Universidade Federal de Minas Gerais (UFMG) \\ Orcid: https://orcid.org/0000-0002-2122-0382 / E-mail: pripismoc@hotmail.com \\ BEATRIZ NAJELA EKATERINA RIBEIRO DA SILVA \\ Graduanda em Ciências Contábeis - Universidade Federal de Minas Gerais (UFMG) \\ Orcid: 0000-0002-5713-7871 / E-mail: beatriznajela@gmail.com \\ CÁSSIA OLIVEIRA FERREIRA \\ Mestranda em Controladoria e Contabilidade - Universidade Federal de Minas Gerais (UFMG) \\ Orcid: 0000-0003-4779-8497 / E-mail: cassiaoliveiraf26@gmail.com \\ Submissão: 12/08/2020. Revisão: 25/10/2020. Aceite: 26/11/2020. Publicação: 29/12/2020. \\ DOI: http://dx.doi.org/10.22277/rgo.v14i1.5724
}

\section{RESUMO}

O estudo desenvolvido visou analisar os efeitos da COVID-19 sobre a sustentabilidade econômico-financeira das empresas brasileiras de capital aberto. Para o desenvolvimento da pesquisa, foram coletados dados da Plataforma Economática ${ }^{\circledR}$ e da Brasil, Bolsa, Balcão (B3). Empregaram-se as seguintes técnicas de análise de dados: análise de conteúdo, estatística descritiva, testes de Kolmogorov-Smirnov e Wilcoxon, coeficiente de correlação de Spearman e análise de regressão múltipla. Como principais resultados da pesquisa, destacam-se: (a) a forte influência do período de evolução da COVID-19 sobre a sustentabilidade econômicofinanceira das empresas; (b) a constatação de elevadas perdas de valor dessas organizações no mercado de capitais; (c) a verificação da queda significativa da rentabilidade das empresas e o aumento do nível de endividamento das mesmas; e (d) a observação de que variáveis determinantes clássicas de estrutura de capital explicaram bem o fenômeno de captação de recursos no período. Como principais contribuições da pesquisa, citam-se: (i) análise da influência da COVID-19 sobre as operações das empresas, por meio de dados de mercado e das suas demonstrações financeiras; (ii) perspectiva (via notas explicativas) das empresas sobre os efeitos da pandemia sobre suas operações e medidas adotadas para mitigá-los; e (iii) enfoque à captação de recursos externos para a manutenção das atividades das empresas durante a pandemia.

Palavras-chave: Pandemia de COVID-19. Sustentabilidade econômico-financeira. Empresas brasileiras. 


\section{ABSTRACT}

This paper presents the results of a research that aimed at analyzing the effects of COVID-19 over the financial sustainability of Brazilian public companies. We collected data from Economática ${ }^{\circledR}$ and Brasil, Bolsa, Balcão (B3) and use the following techniques to analyze them: content analysis, descriptive statistics, Kolmogorov-Smirnov's test, Wilcoxon's test, Spearman's correlation, and linear regression. We verified the following main results: (a) there was a high effect of COVID-19 period over the financial sustainability of Brazilian public companies; (b) the analyzed companies lost much value in capital market; (c) we observed a deterioration in several financial ratios, especially a significant reduction in profitability and a significant increase in debt levels; and (d) we identified that the classic determinants of capital structure could explained the debt increasing during pandemic. The research offers three major contributions: (i) it employed market and financial data for analyzing the effects of COVID-19 over the companies' operations; (ii) it enhanced the companies' standpoint of the pandemic's effects (and actions to mitigate them); (iii) and it emphasizes the companies' capital raising to maintain their operations during pandemic.

Keywords: COVID-19 Pandemic. Financial sustainability. Brazilian public companies.

\section{INTRODUÇÃO}

A COVID-19 vem se espalhando rapidamente pelo mundo em 2020 (JOHNS HOPKINS UNIVERSITY, 2020). Ashra (2020) classifica a pandemia de COVID-19 como um evento raro e sem precedentes. Diante disso, estudos como o de Ferguson et al. (2020) desenvolveram uma série de simulações sobre o avanço da doença, indicando o isolamento social como principal medida governamental para evitar um colapso do sistema de saúde dos países. Todavia, além de questões sanitárias, a pandemia de COVID-19 iniciou uma grande crise financeira global (SALISU; VO, 2020; HEYDEN; HEYDEN, 2020).

Em março, período no qual várias bolsas ocidentais precificaram o potencial efeito da pandemia, as empresas que compõe os índices de mercado perderam aproximadamente $30 \%$ de seu valor, sendo que, no Brasil, tal queda chegou a 31,5\% (SALISU; VO, 2020; BRASIL, BOLSA, BALCÃO [B3], 2020). Dados preliminares estimam um recuo de até $7 \%$ do Produto Interno Bruto (PIB) brasileiro em 2020 (FERNANDES, 2020). Tal dado é reforçado pelo Relatório Focus (2020) do Banco Central do Brasil (BACEN) do início do mês de julho, que indicou um declínio de 6,5\%. Porém, projeções mais pessimistas, como as do Fundo Monetário Internacional (FMI), indicam uma queda de mais de $9 \%$ no PIB nacional.

Nesse contexto, investidores e gestores tomam decisões diante de uma série de incertezas (SALISU; VO, 2020). Hassan et al. (2020) destacam que diversos gestores empresariais ao redor do mundo demonstraram uma preocupação em como lidar com a pandemia de COVID-19 desde o início do ano, tentando compreender como ela iria afetar seus negócios especificamente, assim como quais medidas poderiam ser implementadas pelas próprias empresas. Fernandes (2020) ressalta que, para auxiliar a mitigar os efeitos negativos da pandemia nas empresas, os governos teriam que subsidiá-las, tentando manter empregos e consumo.

No Brasil, destacam-se como medidas governamentais nesse sentido: (a) a Medida Provisória n.o 936, de 1으 de abril de 2020, posteriormente, convertida na Lei no 14.020, de 6 de julho de 2020 que instituiu o Programa Emergencial de Manutenção do Emprego e da Renda; (b) a Emenda Constitucional $n^{\circ}$. 106, de 7 de maio de 2020, que instituiu regime 
extraordinário fiscal, financeiro e de contratações para enfrentamento de calamidade pública nacional decorrente de pandemia; e (c) o Decreto n. 10.350/2020, que criou a Conta-covid, que tem como foco uma operação de mercado para o setor elétrico, estruturada sob a forma de um empréstimo sindicalizado lastreado por ativos tarifários que transitam pela Conta de Desenvolvimento Energético (BRASIL, 2020a; 2020b; 2020c). Heyden e Heyden (2020), no entanto, ressaltam que há diferenças significativas dos efeitos das políticas fiscal e monetária sobre os mercados ao redor do mundo.

Nesse sentido, o enfrentamento à COVID-19 não é entendido apenas como uma ação sanitária, mas também econômica. Os efeitos da pandemia nos negócios, assim como as medidas tomadas pelas organizações e governos, podem ser observados a partir das informações constantes nas demonstrações financeiras dessas empresas. Andekina e Rakhmetova (2013) ressaltam que tais informações refletem tanto fatores internos quanto externos às empresas, sendo bastante relevante usá-las nas análises econômico-financeira delas, em especial, em momentos de crise.

Diante de todo o exposto, o estudo teve como objetivo analisar os efeitos da pandemia de COVID-19 sobre a sustentabilidade econômico-financeira das empresas brasileiras de capital aberto. Para o desenvolvimento da pesquisa, primeiramente, foi importante identificar os efeitos da pandemia de COVID-19 sobre as operações das companhias brasileiras, assim como as medidas empregadas por elas para mitigá-los. É relevante destacar que, tal como apresentado, tais efeitos da pandemia foram rapidamente refletidos nos preços das ações das empresas no mercado de capitais (SALISU; VO, 2020).

Salienta-se, porém, que esses efeitos também podem ser analisados sob diferentes perspectivas da sustentabilidade econômico-financeira dessas empresas a partir da análise das demonstrações suas financeiras. Nicoleta-Cornelia et al. (2012) enfatizam que se pode compreender diversos aspectos das operações das empresas, a partir de uma análise econômico-financeira das mesmas realizada por meio dessas demonstrações. Dentre as principais técnicas para desenvolver tal análise, o emprego de indicadores econômicofinanceiros está entre as principais. Padoveze e Benedicto (2014) ressaltam que tais indicadores evidenciam sinteticamente diversas dimensões do desempenho econômicofinanceiro das organizações, a partir de suas operações.

Porém é importante destacar que, durante a pandemia de COVID-19, é esperado uma menor disponibilidade de recursos advindos do desenvolvimento das operações das empresas durante a vigência de medidas de isolamento social e o aumento da incerteza dos agentes econômicos, tal como enfatizam Salisu e Vo (2020). Desse modo, esperar-se-á uma maior necessidade de captação de recursos via instituições financeiras por parte das empresas estudadas para se manterem ativas. Assim, é esperado que empresas com determinadas características (em especial, àquelas que sinalizem maior credibilidade frente às instituições financeiras) consigam obter mais facilmente recursos emprestados que outras (PEROBELLI; FAMA, 2002).

Novamente, tanto os efeitos das captações, como tais características das empresas podem ser obtidas a partir das demonstrações financeiras das mesmas (FRANK; GOYAL, 2009). Dessa forma, verifica-se que, a partir de informações das empresas (tanto qualitativas quanto quantitativas), é possível compreender os efeitos da pandemia de COVID-19 sobre a sustentabilidade econômico-financeira das companhias abertas brasileiras.

Essa pesquisa se justifica sob diversas perspectivas. Primeiramente, tem-se o dramático efeito da pandemia de COVID-19, afetando pessoas e empresas em todo o mundo (ASHRA, 2020; HEYDEN; HEYDEN, 2020). Ademais, as medidas para conter os efeitos mais 
danosos da pandemia têm fortes impactos negativos e sem precedentes sobre empresas e o mercado financeiro de uma forma geral (SALISU; VO, 2020). Salienta-se, ainda, o fato de que não está claro como as empresas serão afetadas pela pandemia de COVID-19, já que seus efeitos nos negócios se mostram bastante diversos de pandemias anteriores (HASSAN et al., 2020).

Além disso, por ser um fenômeno recente, ainda não são encontrados estudos nacionais sobre os efeitos da pandemia em diferentes aspectos do desempenho econômicofinanceiros no nível das empresas, sendo que a análise dessas informações é muito importante, especialmente, em tempos de crises (ANDEKINA; RAKHMETOVA, 2013). Por fim, especificamente sobre a COVID-19, Heyden e Heyden (2020) destacam o papel de indicadores econômico-financeiros na análise dos efeitos da pandemia sobre as empresas, uma vez que alguns desses indicadores determinaram a forma como os mercados precificaram os ativos em diferentes mercados de capitais.

A pesquisa desenvolvida contribui em diversos aspectos para a discussão acadêmica e profissional dos efeitos da COVID-19 sobre a sustentabilidade econômico-financeira das empresas. Primeiramente, analisou-se a influência da pandemia sobre as operações das empresas tanto empregando dados de mercado quanto das demonstrações financeiras delas. Ademais, enfocou-se a perspectiva interna (via notas explicativas) das empresas sobre os efeitos da pandemia sobre suas operações e quais estratégias estariam sendo empregadas para mitigá-los. Além disso, realçou-se a busca por captação de recursos externos para a manutenção das atividades das empresas, tal como se demonstrou que variáveis determinantes clássicas de estrutura de capital poderiam explicar tal fenômeno.

\section{REFERENCIAL TEÓRICO}

\subsection{COVID-19: EFEITOS SOBRE O MERCADO DE CAPITAIS}

A pandemia de COVID-19 afetou diretamente os negócios em todo o mundo. Conforme Salisu e Vo (2020), a necessidade de isolamento social, a ruptura de cadeias de suprimentos, a menor confiança do consumidor, dentre outros eventos associados à pandemia, afetaram as empresas globalmente. Esses autores afirmam que as notícias relacionadas à pandemia passaram a afetar praticamente todos os mercados de capitais ao redor do mundo, sendo precificadas. Nesse sentido, Heyden e Heyden (2020) ressaltam que a pandemia gerou um efeito negativo sem precedentes em tais mercados.

No Brasil, tal como esperado com base nos autores supracitados, o lbovespa, principal índice da B3, perdeu mais de 31,5\% de pontos ao longo do mês de março de 2020 (Figura 1a). Assim como esperado com base no exposto por Salisu e Vo (2020), o pessimismo do mercado financeiro em março também afetou a economia real e suas previsões. Tal situação é apresentada pelo Relatório Focus (2020), cuja evolução demonstra que a perspectiva dos agentes do mercado para o PIB brasileiro no início de janeiro de 2020 era de 2,3\% de crescimento, reduzindo-se constantemente ao longo do tempo para uma perspectiva de redução de $6,5 \%$ em julho do mesmo ano (Figura 1 b). Nesse sentido, um relatório de junho do FMI estima uma queda do PIB brasileiro de 9,1\% em 2020 (FMI, 2020). 
Figura 1a: Redução do valor do Ibovespa em 2020

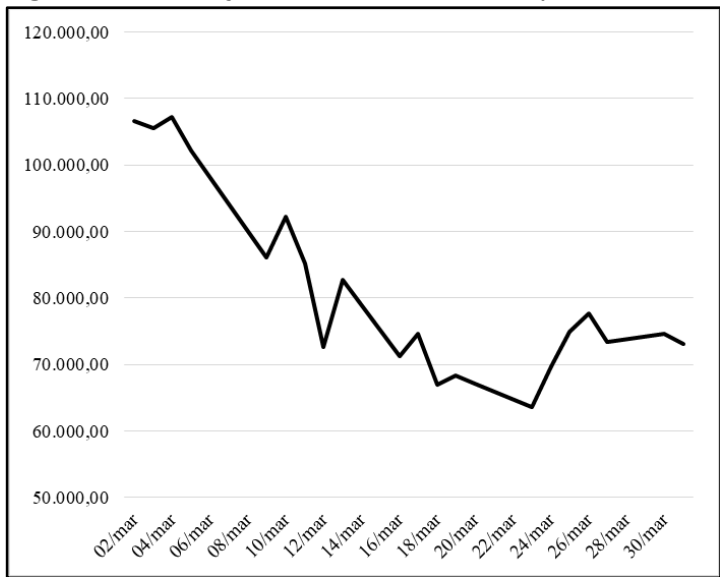

Fonte: adaptado de B3 (2020).

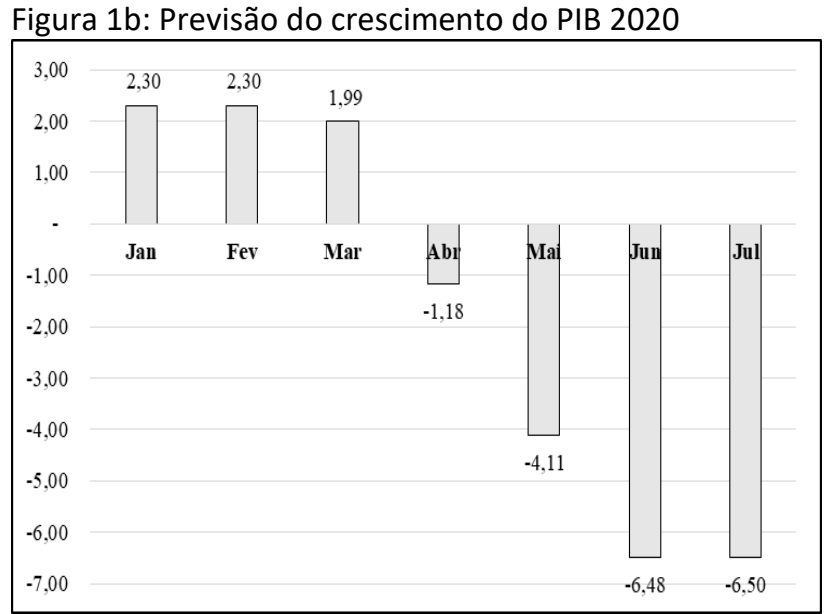

Fonte: adaptado de Relatório Focus (2020).

A precificação das informações sobre a pandemia no mercado de capitais, tal como ressaltado por Salisu e Vo (2020) pode ser explicada sob a perspectiva da hipótese de mercado eficiente (HME), explanada nos artigos seminais de Fama (1970; 1991). Ross et al. (2015) ressaltam que essa hipótese afirma que o "os preços dos títulos refletem integralmente as informações disponíveis". Dessa forma, é possível dizer que o reflexo das informações sobre a pandemia nos preços das ações das empresas, representa a eficiência de mercado em sua forma semiforte, conforme a definição de Fama (1991). Neste caso, as informações públicas da pandemia seriam refletidas no preço das ações.

Porém, salienta-se que a Figura 1a apresentada anteriormente se refere ao índice de mercado Ibovespa, que representa um conjunto de empresas, cujas negociações de títulos na B3 apresentam determinadas características ligadas especialmente à liquidez e ao volume (B3, 2020). Assim, é esperado que diferentes empresas apresentem perdas distintas em seus valores de mercado, considerando que elas não são afetadas da mesma forma pela pandemia e pelas medidas para lidar com o avanço da doença. Dessa forma, as informações públicas sobre as operações das empresas e sobre os efeitos da pandemia seriam precificadas nos títulos em março de forma individual para cada organização conforme a HME, de acordo com a exposição de suas operações aos efeitos da pandemia. Exemplificando, a priori, esperar-seá que empresas pertencentes ao setor de Utilidade Pública da B3 sejam menos afetadas em suas operações, por prestarem serviços usualmente essenciais e contarem, em muitos casos, com participação estatal. Por outro lado, em setores como o de Consumo cíclico (que inclui hotelaria e viagens) ou Bens Industriais (que inclui as companhias áreas e de transporte rodoviário), é de se esperar maiores efeitos negativos (e consequente queda nos preços dos ativos), devido ao isolamento social e, inclusive, a proibição de algumas operações (por não serem serviços essenciais). Assim, espera-se que empresas destes últimos setores citados reportem mais efeitos negativos da pandemia do que as daquele setor, por exemplo. Com base no exposto, desenvolveu-se a Hipótese 1 do estudo:

H1: Há uma relação positiva e significativa entre as empresas que mais perderam valor de mercado em março e aquelas mais expostas aos efeitos negativos da pandemia.

\subsection{COVID-19: EFEITOS SOBRE O DESEMPENHO ECONÔMICO-FINANCEIRO DAS EMPRESAS}

As consequências da pandemia sobre as operações das empresas podem ser mensuradas não apenas com base no comportamento dos preços de suas ações no mercado financeiro, mas também por meio das informações constantes de suas demonstrações 
Ewerton Alex Avelar, Priscila Oliveira Ferreira, Beatriz Najela Ekaterina Ribeiro da Silva e Cássia Oliveira Ferreira

financeiras. Segundo a Estrutura Conceitual para Relatório Financeiro emitida pelo Comitê de Pronunciamentos Contábeis (CPC), o objetivo dessas demonstrações é:

\begin{abstract}
fornecer informações financeiras sobre os ativos, passivos, patrimônio líquido, receitas e despesas da entidade que reporta [...] que sejam úteis aos usuários das demonstrações contábeis na avaliação das perspectivas para futuros fluxos de entrada de caixa líquidos para a entidade que reporta e na avaliação da gestão de recursos da administração sobre os recursos econômicos da entidade (CPC, 2019).
\end{abstract}

Salienta-se que tais demonstrações são, usualmente, o subsídio fundamental para a análise econômico-financeira das organizações. De acordo com Nicoleta-Cornelia et al. (2012), o principal objetivo da análise econômico-financeira é compreender a situação da organização, no intuito de subsidiar as futuras decisões de alocação de recursos. Nesse sentido, pode-se dizer que essa análise visa interpretar o passado e o presente da organização e, assim, prever e se preparar para as suas condições futuras (LEE; LIN; SHIN, 2012). Andekina e Rakhmetova (2013) ressaltam que as informações empregadas em análises econômicofinanceiras são representativas de fatores tanto internos quanto externos às empresas.

Pode-se dizer que as principais técnicas de análise econômico-financeira estão relacionadas ao emprego de indicadores econômico-financeiros (DE LIMA TAVARES; SILVA, 2012). Conforme Fernandes, Ferreira e Rodrigues (2014), tais indicadores são calculados a partir das demonstrações financeiras e possibilitam que analistas ou gestores estudem diversos aspectos da situação econômico-financeira da organização, propiciando ações de planejamento e controle. Dessa forma, verifica-se que tais indicadores possibilitam sintetizar informações das demonstrações, munindo os diferentes usuários das demonstrações citados pelo CPC (2019) com informações úteis sobre a empresa.

É possível dizer também, que esse tipo de análise das empresas é especialmente relevante em períodos de crises (ANDEKINA; RAKHMETOVA, 2013). Especificamente, sobre a pandemia de COVID-19, Heyden e Heyden (2020) destacam que os efeitos da mesma sobre as empresas, podem ser analisados sob a perspectiva de indicadores econômico-financeiros. Esses autores observaram que diferentes indicadores influenciaram de formas distintas a precificação de ativos após o relato da primeira morte relacionada à COVID-19 em um país, assim como os efeitos de políticas governamentais. Empresas com maiores níveis de liquidez e tangibilidade apresentaram melhores desempenho no mercado no início da pandemia do que as demais. Porém, os resultados referentes à lucratividade foram conflitantes.

Dentre os principais grupos de indicadores econômico-financeiros tradicionalmente utilizados na análise de empresas, podem ser citados: (i) liquidez - visam fornecer informações sobre a capacidade da organização em pagar suas dívidas, comparando os seus direitos realizáveis e as suas exigibilidades (SILVA, 2013); (ii) ciclos (atividades) - visam avaliar quão eficientemente os ativos da organização são administrados (ROSS et al., 2015); (iii) endividamento (ou estrutura de capital) - demonstram a porcentagem dos ativos financiada com capital de terceiros e próprios, ou se a empresa tem dependência de recursos de terceiros (PADOVEZE; BENEDICTO, 2014); e (iv) rentabilidade/lucratividade - indicam o retorno que a organização está obtendo de suas atividades (SILVA, 2013). Observa-se que os diferentes grupos de indicadores visam apresentar informações sobre as distintas dimensões do desempenho econômico-financeiro das empresas, possibilitando uma ampla variedade de perspectivas para análise prospectiva das mesmas, conforme enfatizado por Nicoleta-Cornelia et al. (2012). Ademais, tal como destacado por Andekina e Rakhmetova (2013), tais indicadores possibilitam a análise simultânea de fatores tanto internos quanto externos às empresas. Um indicador ligado ao endividamento da empresa, por exemplo, pode explicitar 
Efeitos da pandemia de COVID-19 sobre a sustentabilidade econômico-financeira de empresas brasileiras

simultaneamente tanto o nível de risco assumido por gestores em busca de melhores retornos (fator endógeno) quanto o custo do capital de terceiros dadas as condições de mercado (fator exógeno).

Salienta-se que há diversas classificações de tais indicadores, de acordo com diferentes autores. Dessa forma, o Quadro 1 apresenta um resumo deles conforme a Plataforma Economática ${ }^{\circledR}$ (usada para coleta de parte dos dados analisados no estudo). Ressalta-se que a referida plataforma inclui uma série de informações financeiras como indicadores, tais como o lucro antes dos juros, imposto de renda, depreciação e amortização (do inglês, earnings before interest, taxes, depreciation and amortization - EBITDA), receita líquida, dentre outras, sendo todas, para fins deste trabalho, tratadas como indicadores econômico-financeiros.

Quadro 1- Indicadores Financeiros

\begin{tabular}{|l|l|}
\hline \multicolumn{1}{|c|}{ Grupo } & \multicolumn{1}{c|}{ Indicadores (Siglas) } \\
\hline $\begin{array}{l}\text { Endividamento } \\
\text { capital) }\end{array}$ & $\begin{array}{l}\text { Dívida total líquida (DivTtLq); Dívida total bruta (DivTtBruta); Dívida bruta sobre ativo } \\
\text { (div_brAtivo); Dívida bruta sobre patrimônio líquido (divbPL); Dívida líquida sobre } \\
\text { patrimônio líquido (divIPatL); estrutura de capital (sobre o patrimônio líquido) } \\
\text { (estcapPL); Dívida líquida sobre o EBITDA (DvLEBITDA); Dívida de curto prazo sobre } \\
\text { dívida total (DiCPDivTotal); Exigível sobre ativo (ExAT); Exigível sobre o patrimônio } \\
\text { líquido (ExPL); Exigível sobre receita (ExRec); Ativo fixo sobre patrimônio líquido } \\
\text { (AfixoPL); e Investimento sobre patrimônio líquido (InvestPL). }\end{array}$ \\
\hline Liquidez & $\begin{array}{l}\text { Liquidez geral (LG); Liquidez corrente (LC); Liquidez seca (LS); Capital de giro (CapiGir); } \\
\text { e Capital empregado (CapEmp). }\end{array}$ \\
\hline Ciclos & $\begin{array}{l}\text { Prazo médio de estocagem (PME); Prazo médio de pagamento a fornecedores (PMP); } \\
\text { Prazo médio de recebimento de clientes (PMR); Ciclo financeiro (CF); e Ciclo } \\
\text { operacional (CO). }\end{array}$ \\
\hline Rentabilidade & $\begin{array}{l}\text { EBITDA; Lucro antes dos tributos somados às despesas financeiras líquidas } \\
\text { (LAIR_DFL); Giro do ativo (GA); Giro do patrimônio líquido (GPL); Margem EBIT } \\
\text { (MEBIT); Margem líquida (ML); Margem EBITA (MEBTIDA); Rentabilidade do ativo } \\
\text { (ROA); Rentabilidade sobre o capital investido (ROIC); Capital investido (InvesCap); } \\
\text { Alavancagem financeiro (AF); Alavancagem operacional (AOp); e Receitas (Rec). }\end{array}$ \\
\hline
\end{tabular}

Fonte: Plataforma Economática ${ }^{\circledR}$ (2020).

Tal como apresentado anteriormente, a pandemia de COVID-19 impactou os negócios especialmente a partir da redução drástica da atividade econômica em seus diversos níveis (regional, nacional e internacional). Com isso, esperam-se múltiplos efeitos sobre os ciclos operacional e financeiro das empresas. Padoveze e Benedicto (2014) destaca que os principais indicadores de ciclos seriam: o PME, o PMR e o PMP. Assim, a queda abrupta de demanda em diversos setores devido à pandemia levaria empresas a manterem um maior nível de estoques (elevando o PME). Sem giro dos estoques e geração de caixa, os pagamentos das empresas tenderiam a ficar atrasados junto a fornecedores, elevando o PMP. Por outro lado, é de se esperar que clientes da mesma cadeia também enfrentem situações semelhantes, tendo dificuldades de honrar os compromissos com a empresa, o que elevaria o PMR e, consequentemente o ciclo operacional. Já o efeito no ciclo financeiro dependeria magnitude do efeito de cada um dos três indicadores citados por Padoveze e Benedicto (2014). Porém, como seriam dois pressionando o seu aumento (PME e PMR) em contraposição a apenas um que incentiva sua redução (PMP), também se verifica uma tendência de elevação. Com base nessas suposições, desenvolveu-se a Hipótese 2a:

H2a - O período de evolução da pandemia de COVID-19 está associado ao aumento dos indicadores relacionados aos ciclos das empresas. 
A partir da redução de circulação de pessoas de uma forma geral, é esperado uma redução no nível de receitas das empresas. Porém, apesar de as receitas serem usualmente variáveis (em função do nível de vendas), muitos dos custos de suas estruturas são fixos, e muitos elementos tendem a ter um comportamento sticky (neste caso, traduzido pela literatura nacional como "assimétrico"), tais como salários e encargos (ANDERSON; BANKER; JANAKIRAMAN, 2003; GOLDEN; MASHRUWALAB; PEVZNER, 2019). Dessa forma, a queda significativa e rápida das vendas tende a reduzir a rentabilidade das empresas, diante da redução drástica das receitas não serem necessariamente acompanhada pela queda dos custos na mesma proporção (ou seja, de forma simétrica). Com base nessas suposições, desenvolveu-se a Hipótese $2 \mathrm{~b}$ :

H2b - O período de evolução da pandemia de COVID-19 está associado à redução da rentabilidade das empresas.

A baixa rentabilidade por sua vez, advinda da redução drástica das receitas e a persistência dos custos, pode levar às empresas a restrições em seu caixa para honrar seus compromissos (pagamento a fornecedores, funcionários, juros, etc.). Uma maneira de preencher essa lacuna seria por meio da aquisição de empréstimos e financiamentos (PADOVEZE; BENEDICTO, 2014). Dessa forma, espera-se um aumento do endividamento das empresas, especialmente, no curto prazo, durante o período de pandemia. Com base nessas suposições, desenvolveu-se a Hipótese 2c:

H2c - O período de evolução da pandemia de COVID-19 está associado ao aumento do endividamento das empresas.

Por outro lado, tanto o maior nível de endividamento das empresas quanto o aumento de seu ciclo operacional tendem a afetar a liquidez delas em diferentes horizontes temporais. Porém, a direção do efeito geral não é tão clara, considerando que o nível de endividamento tende a afetar os passivos e ativos da empresa, enquanto o ciclo operacional, seus ativos. Com base nessas suposições, desenvolveu-se a Hipótese $2 \mathrm{~d}$ :

H2d - O período de evolução da pandemia de COVID-19 está associado à alteração da liquidez das empresas.

Por fim, com base na expectativa do aumento do valor do endividamento das empresas no período fundamentada nos aspectos supracitados, o estudo ora apresentado também visou compreender as variáveis que poderiam explicar o maior ou menor nível de captação de recursos de terceiros. Com base na literatura sobre determinantes de estrutura de capital, foram propostas hipóteses que podem explicar a variação do endividamento das empresas entre o quarto trimestre de 2019 e o primeiro trimestre de 2020. Tais hipóteses foram baseadas nas variáveis mais consagradas na literatura sobre o tema, quais sejam: tamanho da empresa (TAM), crescimento (CRESC), lucratividade (LUC), tangibilidade (TANG), singularidade (SING), escudo fiscal não proveniente de dívida (EFNPD) e risco (RISC) (TITMAN; WESSELS, 1988; RAJAN; ZINGALES, 1995; PEROBELLI; FAMA, 2002; FAMA; FRENCH, 2005; FRANK; GOYAL, 2009). Seguem-se as seguintes hipóteses propostas com base nos autores que analisaram tais variáveis sobre a perspectiva da teoria do trade-off:

H3a - o maior porte da empresa é significativa e positivamente relacionado a sua maior obtenção de recursos no período de evolução da pandemia.

$\mathrm{H} 3 \mathrm{~b}$ - a maior taxa de crescimento da empresa é significativa e negativamente relacionada a sua maior obtenção de recursos no período de evolução da pandemia. 
$\mathrm{H} 3 \mathrm{c}$ - a maior lucratividade da empresa é significativa e positivamente relacionada a sua maior obtenção de recursos no período de evolução da pandemia.

H3d - a maior tangibilidade da empresa é significativa e positivamente relacionada a sua maior obtenção de recursos no período de evolução da pandemia.

$\mathrm{H} 3 \mathrm{e}$ - a maior singularidade da empresa é significativa e negativamente relacionada a sua maior obtenção de recursos no período de evolução da pandemia.

H3f - o maior nível de escudo fiscal não proveniente de dívida da empresa é significativo e negativamente relacionado a sua maior obtenção de recursos no primeiro trimestre de 2020.

$\mathrm{H} 3 \mathrm{~g}$ - o maior nível de risco empresa é significativo e negativamente relacionado a sua maior obtenção de recursos no período de evolução da pandemia.

\section{METODOLOGIA}

Esta pesquisa pode ser classificada como quantitativa, descritiva, correlacional e explicativa (SAMPIERI; COLLADO; LUCIO, 2006). A população do estudo se referiu às empresas brasileiras de capital aberto. A amostra, por sua vez, restringiu-se às empresas que disponibilizaram os dados demandados para a realização do estudo nas duas fontes usadas para coleta dos mesmos: Plataforma Economática ${ }^{\circledR}$ e o site da B3. Dessa forma, a amostra foi composta pelas empresas cujas demonstrações financeiras e suas notas explicativas estavam disponíveis em ambas as fontes de dados.

A coleta, o tratamento e a análise de dados podem ser divididas em duas etapas desenvolvidas paralelamente. Primeiramente, descreve-se a coleta de dados na B3. Neste caso, objetivou-se coletar dados nas notas explicativas das empresas referentes ao primeiro trimestre de 2020 (período de evolução da pandemia). Notas explicativas podem ser entendidas como "informações complementares às demonstrações contábeis, [...] que podem ser expressas tanto na forma descritiva como na forma de quadros analíticos, ou mesmo englobar outras demonstrações contábeis que forem necessárias para o melhor entendimento dos resultados e da situação" econômico-financeira da empresa (GELBCKE et al., 2018, p. 659).

As notas explicativas de cada empresa foram baixadas no formato PDF do site da B3, no intuito de se obterem informações das empresas sobre os efeitos da pandemia sobre suas operações e as medidas tomadas para mitigá-los. Usaram-se as seguintes palavras-chave no mecanismo de busca do software Adobe Acrobat Reader DC (versão 2020.013.200064) para verificar esses aspectos em relação à pandemia nas notas: "pandemia", Corona" e "Covid".

Após a seleção dos trechos sobre a pandemia em cada nota explicativa, foi realizada uma leitura deles para se identificar os efeitos da COVID-19 sobre as operações da empresa, assim como as medidas de mitigação desses efeitos. Tais trechos foram categorizados de acordo com a técnica de análise de conteúdo, tal como proposto por (BARDIN, 2016). Salientase que foram criadas inicialmente duas grandes categorias: efeitos da pandemia e medidas de mitigação. Subcategorias foram criadas posteriormente, de acordo com os dados encontrados. Após essa categorização, os dados foram analisados por meio de técnicas de estatística descritivas com base em Mann (2007), empregando o aplicativo Excel do Microsoft 365.

Por sua vez, no que se refere à Plataforma Economática ${ }^{\circledR}$, esta foi empregada para se coletarem os dados referentes às demonstrações financeiras. Neste caso, foram selecionados 
todos os indicadores econômico-financeiros disponibilizados pelas empresas dos três últimos trimestres disponíveis: terceiro trimestre de 2019 (3T19), quarto trimestre de 2019 (4T19) e primeiro trimestre de 2020 (1T20) (período de evolução da pandemia). Este último é aquele no qual se espera verificar diferenças estatisticamente significativas em relação ao anterior, devido aos primeiros efeitos da pandemia de COVID-19. Também foi coletada a variável "valor de mercado" das empresas, para analisar os efeitos da pandemia sobre a perspectiva dos investidores. Tais dados foram baixados da referida plataforma no formato ".xlsx" e inicialmente tratados no aplicativo Excel do Microsoft 365.

Para análise dos indicadores econômico-financeiros, além da estatística descritiva, também foi empregado o teste de Kolmogorov-Smirnov para avaliar a normalidade das variáveis. Com base no resultado do referido teste, observou-se que nenhuma variável apresentou distribuição normal nos períodos analisados. Dessa forma, optou-se por empregar, a priori, técnicas não paramétricas de análise dos dados, tal como indicado por Mann (2007). Para analisar a associação entre os efeitos da pandemia e as perdas das empresas em março $(\mathrm{H} 1)$, optou-se por aplicar o coeficiente de correlação de Spearman (MAROCO, 2010). Já no caso da análise da variação dos indicadores econômico-financeiros entre os trimestres (3T19 e 4T19, e 4T19 e 1T20), optou-se pelo teste de Wilcoxon para amostras pareadas ( $\mathrm{H} 2 \mathrm{a}, \mathrm{H} 2 \mathrm{~b}, \mathrm{H} 2 \mathrm{c}$ e H2d). Tal teste, segundo Maroco (2010), é uma alternativa não-paramétrica ao teste $t$ de Student quando o pressuposto de distribuição normal das variáveis não se verifica ou são platicúrticas (caso da maior parte dos dados analisados).

Já no que se refere à análise de variáveis determinantes da captação de recursos no período da pandemia ( $\mathrm{H} 3 \mathrm{a}, \mathrm{H} 3 \mathrm{~b}, \mathrm{H} 3 \mathrm{c}, \mathrm{H} 3 \mathrm{~d}, \mathrm{H} 3 \mathrm{e}, \mathrm{H} 3 \mathrm{f}$ e H3g), optou-se por empregar a análise de regressão múltipla. Esta, pode ser compreendida como uma técnica estatística empregada para se analisar a relação entre uma variável dependente e diversas variáveis independentes (HAIR JR. et al., 2009). Para a aplicação de tal técnica multivariada, que exige uma série de pressupostos, foram retiradas algumas observações tratadas como outliers. A Equação 1 apresenta o modelo estimado. Nela, o subscrito $i$ equivale à empresa, $\varepsilon$ equivale ao termo de erro do modelo, $b_{0}$ equivale ao intercepto e $b_{n}$ aos coeficientes estimados. Salienta-se que a variável dependente foi o logaritmo natural da variação da dívida bruta da empresa durante o período da pandemia. Por fim, a Figura 2 apresenta gráfica e sinteticamente todos os procedimentos metodológicos desenvolvidos no estudo: fontes de dados, coleta dos mesmos, bancos de dados desenvolvidos, assim como as técnicas de tratamento e análise, e as hipóteses testadas. Salienta-se que as técnicas de estatística inferencial empregaram o software R versão 4.0.0 para sua operacionalização.

$$
\begin{gathered}
\operatorname{VDIVBR}_{i}=\beta_{0}+\beta_{1} \times T A M_{i}+\beta_{2} \times \operatorname{CRES}_{i}+\beta_{3} \times L U C_{i}+\beta_{4} \times T A N G_{i}+\beta_{5} \times \operatorname{SING}_{i} \\
+\beta_{6} \times E F N P D_{i}+\beta_{7} \times \operatorname{RISC}_{i}+\varepsilon_{i}
\end{gathered}
$$

Onde: TAM equivale ao logaritmo natural do ativo da empresa; CRES equivale ao crescimento do ativo da empresa no ano; LUC equivale ao EBIT dividido pelo ativo total da empresa; TANG equivale à soma entre os estoques e o ativo imobilizado da empresa; SING equivale ao ativo intangível dividido pelo ativo total da empresa; EFNPD equivale à soma entre os gastos com amortização e depreciação divididos pelo ativo total; RISC equivale a volatilidade das ações da empresa nos últimos doze meses. 
Figura 2: Procedimentos metodológicos

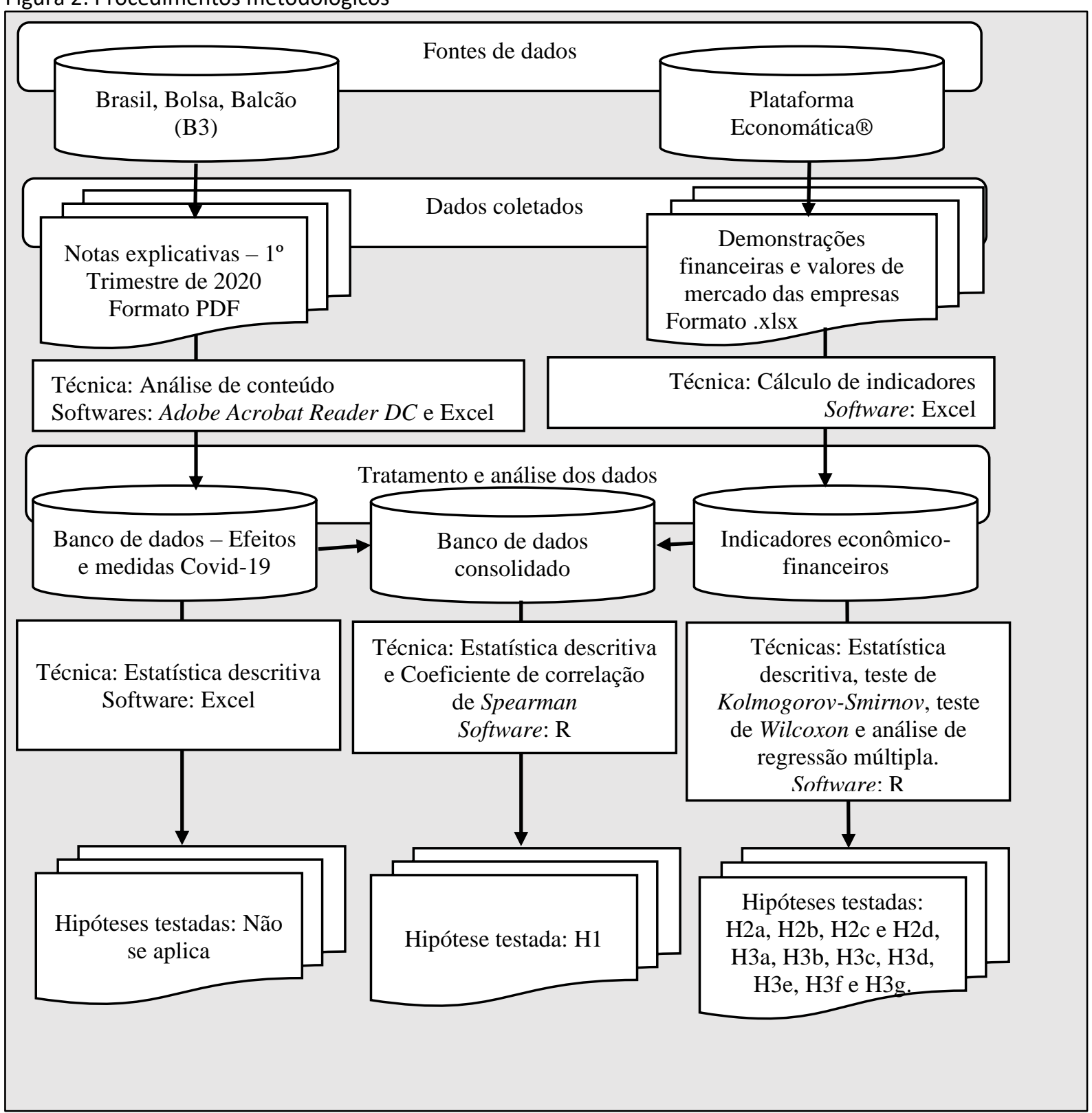

Fonte: elaborada pelos autores (2020).

\section{ANÁLISE DOS RESULTADOS}

\subsection{EFEITOS DA COVID-19 SOBRE AS OPERAÇÕES DAS EMPRESAS E MEDIDAS DE MITIGAÇÃO}

Inicialmente, sob a perspectiva do mercado, a Tabela 1 apresenta a redução dos valores das empresas estudadas ao longo do mês de março. Verifica-se uma perda total de mais de $\mathrm{R} \$ 800$ bilhões em valor de mercado das empresas estudadas em março, o que equivale a aproximadamente $30 \%$ do valor apresentado em fevereiro. Em média, cada empresa estudada perdeu $\mathrm{R} \$ 4,1$ bilhões durante o referido mês. Porém, verifica-se uma perda superior em alguns setores da economia em relação a outros. Verificam-se que as maiores perdas médias ocorreram no setor de Petróleo, gás e biocombustíveis. As medidas de distanciamento social indicadas por Ferguson et al. (2020) afetam a circulação de pessoas e mercadorias, reduzindo o consumo de combustíveis, afetando o potencial de geração de recursos por tais empresas. 
Ewerton Alex Avelar, Priscila Oliveira Ferreira, Beatriz Najela Ekaterina Ribeiro da Silva e Cássia Oliveira Ferreira

Tabela 1 - Redução em Valores das Empresa em março/2020

\begin{tabular}{|c|c|c|c|}
\hline \multirow[t]{2}{*}{ Setor } & \multicolumn{3}{|c|}{ Perda (em milhares de $\mathbf{R} \$$ ) } \\
\hline & Observações & Total & Média \\
\hline Bens industriais & 31 & $-59.878 .139,59$ & $-1.931 .552,89$ \\
\hline Comunicações & 2 & $-11.928 .292,24$ & $-5.964 .146,12$ \\
\hline Consumo cíclico & 46 & $-172.450 .136,40$ & $-3.748 .916,01$ \\
\hline Consumo não cíclico & 15 & $-93.550 .903,75$ & $-6.236 .726,92$ \\
\hline Financeiro & 22 & $-92.704 .015,49$ & $-4.213 .818,89$ \\
\hline Materiais básicos & 15 & $-43.171 .926,04$ & $-2.878 .128,40$ \\
\hline Petróleo, gás e biocombustíveis & 7 & $-179.568 .141,98$ & $-25.652 .591,71$ \\
\hline Saúde & 14 & $-41.185 .736,18$ & $-2.941 .838,30$ \\
\hline Tecnologia da informação & 5 & $-5.561 .012,94$ & $-1.112 .202,59$ \\
\hline Utilidade pública & 36 & $-104.554 .662,28$ & $-2.904 .296,17$ \\
\hline Total & 193 & $-804.552 .966,89$ & $-4.168 .668,22$ \\
\hline
\end{tabular}

Fonte: elaborada pelos autores (2020).

Diversos motivos podem ser as explicações para a redução do valor de mercado das empresas durante o mês de março devido à pandemia de COVID-19. A Tabela 2 apresenta esses efeitos (reais e potenciais) da pandemia segundo as próprias empresas. No total, as empresas listaram 400 citações de efeitos da pandemia sobre suas operações. Salienta-se que as empresas podiam listar mais de um efeito. Nesse caso, houve uma média de 2,07 efeitos reportados por empresa. O principal deles, conforme a Tabela 2, foi a incerteza nas previsões. Uma vez, que se trata de relatórios do primeiro trimestre do ano, quando a pandemia começou a se espalhar rapidamente pelo mundo, faz muito sentido essa dificuldade em prever para tomada de decisões mais assertivas.

Tabela 2 - Lista de Efeitos da Pandemia citadas pelas Empresas

\begin{tabular}{lcc}
\hline \multicolumn{1}{c}{ Efeitos } & \multicolumn{2}{c}{ Frequência } \\
\cline { 2 - 3 } & Absoluta & Relativa (\%) \\
\hline Incerteza para previsões & 135 & 33,75 \\
Queda da demanda & 123 & 30,75 \\
Inadimplência & 93 & 23,25 \\
Proibição de funcionamento & 35 & 8,75 \\
Desvalorização cambial & 14 & 3,50 \\
\hline Total & $\mathbf{4 0 0}$ & $\mathbf{1 0 0 , 0 0}$
\end{tabular}

Fonte: elaborada pelos autores (2020).

O segundo efeito mais listado pelas empresas conforme a Tabela 2 foi a queda da demanda (123 citações ou 30,75\%). Tal situação está inerentemente ligada às práticas de isolamento social adotadas em todo o mundo e que reduziram a demanda de forma generalizada nos mercados, afetando drástica e negativamente a geração de receitas das empresas. Outro efeito bastante citado foi a inadimplência (93 citações ou 23,25\%). Esperase que ela aumente devido a possibilidade de enfrentamento de dificuldades financeiras por empresas parceiras e consumidores. Por fim, também foi citada a proibição de funcionamento de algumas empresas (medidas impostas, principalmente por governos das esferas municipais e estaduais) e a desvalorização cambial, que, conforme o BACEN se valorizou bastante frente ao real em março, prejudicando empresas importadoras e àquelas com dívidas em dólar.

Frente a essa situação, as empresas também apresentaram uma série de medidas para mitigar os efeitos negativos da pandemia sobre as suas operações. A Tabela 3 destaca tais medidas. No total, as empresas listaram 864 medidas para mitigar os efeitos da pandemia sobre suas operações (média de 4,48 medidas reportadas por empresa). Destaca-se, 
inicialmente, que foram reportadas quase o dobro de medidas em notas explicativas do que de efeitos negativos da pandemia. Tal constatação pode ser explicada pela necessidade das empresas de demonstrar a proatividade de sua gestão ao mercado, de forma a minimizar as perdas frentes aos stakeholders (mais notícias positivas em detrimentos das negativas). Inclusive, pela Tabela 3, observa-se que a principal medida citada pelas empresas é o reporte periódico ao mercado (192 citações ou 22,22\%), de forma a reduzir a assimetria de informação sobre a pandemia e seus efeitos sobre elas. Apenas uma empresa da amostra não apresentou tal medida. Nesse caso, a redução da assimetria de informação visa reduzir o risco percebido pelos stakeholders, o que tende a melhorar os fluxos de caixa estimados e, consequentemente, o valor de mercado das empresas segundo Ross et al. (2018).

Tabela 3 - Lista de Medidas citadas pelas empresas para enfrentar a Pandemia

\begin{tabular}{lrr}
\hline \multicolumn{1}{c}{ Medidas } & Frequência & \\
\cline { 2 - 3 } & Absoluta & Relativa (\%) \\
\hline Reporte periódico ao mercado & 192 & 22,22 \\
Segurança dos funcionários & 141 & 16,32 \\
Gestão de caixa e receitas & 122 & 14,12 \\
Renegociação com Clientes e Fornecedores & 94 & 10,88 \\
Redução de custos & 92 & 10,65 \\
Postergação de Tributos & 67 & 7,75 \\
Obtenção de Financiamentos e Empréstimos & 60 & 6,94 \\
Revisão de investimentos projetados & 43 & 4,98 \\
Apoio a Sociedade e Governo & 29 & 3,36 \\
Atendimento de novas demandas & 13 & 1,50 \\
Recebimento de Subsídios do Governo & 11 & 1,27 \\
\hline
\end{tabular}

Fonte: elaborada pelos autores (2020).

Ainda, com base na Tabela 3, observa-se a segurança dos funcionários como a segunda medida mais citada pelas empresas (141 citações ou 16,32\%). Tratam-se de stakeholders essenciais para as empresas e, por se tratar de um vírus que usa os seres humanos como vetores conforme Ferguson et al. (2020), muitas das organizações estudadas destacaram o trabalho remoto de uma série de funcionários e as adaptações do ambiente de trabalho para garantir o isolamento quando atividades à distância não era possível. Novamente, pode-se dizer que há também uma clara sinalização ao mercado, uma vez que a empresa não será questionada pela sociedade por impor condições de trabalhos perigosas aos funcionários, o que poderia afetar sua reputação.

As quatro medidas mais frequentes citadas pelas empresas, podem ser ligadas diretamente à gestão econômico-financeira das empresas. Foram as seguintes medidas: Gestão de caixa e receitas, Renegociação com Clientes e Fornecedores, Redução de custos e Postergação de Tributos, com, respectivamente, 122, 94, 92 e 67 citações. Em todos os casos, observa-se um esforço das empresas para minimizar desembolso de caixa, em um momento no qual paira grandes incertezas sobre a demanda, assim como uma busca por garantir um mínimo de entrada de recursos. Ainda no que se refere a recursos, destacam-se a busca por empréstimos e financiamentos (60 citações ou 6,94\%), assim como a busca de subsídios governamentais (11 citações ou 1,27\%). Neste caso, as empresas destacaram a obtenção de mais de $\mathrm{R} \$ 75$ bilhões em empréstimos e financiamentos e subsídios governamentais de mais de $\mathrm{R} \$ 47,5$ bilhões. Outras medidas citadas foram a revisão de investimentos projetados, o 
apoio à sociedade e ao governo, e o atendimento de novas demandas. No caso desta última medida, trata-se de uma busca de oportunidade que apareceram devido à pandemia.

Por fim, visou-se analisar se há uma relação positiva e significativa entre as empresas que mais perderam valor de mercado em março e aquelas mais expostas aos efeitos negativos da pandemia. Tal relação não foi verificada com base nos dados analisados. Pelo contrário, verificou-se um coeficiente de correlação de Spearman de -0,28 significativo a menos de 1,0\%. É importante destacar que as informações sobre os efeitos da pandemia foram divulgadas pelas próprias empresas de forma voluntária via notas explicativas. Dessa forma, há uma ampla margem para a gestão das empresas apresentarem as informações de acordo com interesses corporativos em relação aos dos demais stakeholders (especialmente, o mercado financeiro). Assim, a constatação do coeficiente negativo pode ser explicada pelo fato de que empresas com maiores perdas optaram evitar expor os efeitos da pandemia sobre suas operações, que já precificados pelo mercado. Por outro lado, empresas com menores perdas, devido à menor percepção de risco por parte dos agentes econômicos, podem ter divulgado um número maior de efeitos visando demonstrar um maior esmero no mapeamento de riscos, ao mesmo tempo em que apresentaram um maior número médio de medidas de mitigação (tal como abordado anteriormente). De qualquer forma, ambas as posturas tendem a influenciar a perspectiva de risco dos stakeholders, evitando uma maior deterioração do valor de mercado. Assim, não é possível ratificar a H1.

\subsection{EFEITOS DA COVID-19 SOBRE O DESEMPENHO ECONÔMICO-FINANCEIRO}

A Tabela 4 apresenta a mediana dos diferentes indicadores econômico-financeiros analisados nos períodos 3T19, 4T19 e 1T20, assim como os resultados do teste de Wilcoxon pareado comparando 3T19 e 4T19 (comparação entre períodos sem pandemia), 4T19 e 1T20 (comparação entre o último período antes da pandemia e aquele de evolução da pandemia). Com base na Tabela 4, verificam-se diferenças estatisticamente significativas entre os indicadores analisados tanto no que se refere à comparação entre 3 T19 e 4T19, quanto na comparação entre 4T19 e 1T20. Porém, há diferenças importantes na comparação entre aqueles primeiros e entre esses últimos períodos. Primeiramente, enquanto existem 15 valores significativos entre os dois períodos de 2019, existem 29 valores significativos na comparação entre 4T19 e 1T20. Ademais, enquanto no caso da comparação entre 3T19 e 4T19 as variações não são tão claras (tal como redução da receita e aumento de alguns indicadores de rentabilidade), a comparação entre os indicadores econômico-financeiros de 4T19 e 1T20 apresentam evidências dos efeitos esperados da pandemia. Dessa forma, as variações nos indicadores desses dois últimos períodos passam a ser analisados de acordo com os seus grupos.

Primeiramente, conforme esperado, verificou-se uma queda significativo do nível de receitas das empresas (Rec). Tal queda pode ser associada à necessidade de isolamento social, à ruptura de cadeias de suprimentos e à menor confiança do consumidor, tal como exposto por Salisu e Vo (2020), e tem fortes implicações nas diferentes dimensões do desempenho econômico-financeiro das empresas. Inicialmente, observa-se um aumento de todos os indicadores relacionados aos ciclos operacionais e financeiros das empresas (PME, PMP e PMR), conforme esperado com base em Padoveze e Benedicto (2014). Dessa forma, em geral, as empresas mantiveram maiores volumes de estoques no último período (associado à queda na demanda) (PME), assim como tiveram que esperar prazos mais longos (que podem ser associados a renegociações ou inadimplência) para receber dos seus clientes (PMR). Por outro lado, destaca-se que o prazo médio de pagamento (PMP) também aumentou em geral, porém, 
não o suficiente para reduzir o ciclo financeiro das empresas (CF), levando-as a manterem maiores recursos financeiros para financiar seus clientes. Tal verificação ratifica a H2a.

Tabela 4 - Teste de Wilcoxon pareado entre os Indicadores Econômico-Financeiros Trimestrais

\begin{tabular}{|c|c|c|c|c|c|}
\hline \multirow[t]{2}{*}{ Variável } & \multicolumn{3}{|c|}{ Medianas } & \multicolumn{2}{|c|}{ Teste de Wilcoxon pareado } \\
\hline & $3 T 19$ & $4 T 19$ & $1 T 20$ & 3Т19-4T19 & $4 T 19-1 T 20$ \\
\hline DivTtLq & $685.573,00$ & $573.000,00$ & $631.722,00$ & $11.951,00^{* *}$ & $4.548,00^{* *}$ \\
\hline DivTtBruta & $1.309 .573,00$ & $1.372 .546,00$ & $1.466 .694,00$ & $9.361,00$ & $2.311,00^{* *}$ \\
\hline div_brAtivo & 28,44 & 27,52 & 28,70 & $11.107,00^{* *}$ & $3.840,00^{* *}$ \\
\hline $\operatorname{div} \bar{b} P L$ & 57,57 & 58,95 & 62,68 & $9.772,00^{*}$ & $4.587,00^{* *}$ \\
\hline divlPatL & 33,43 & 34,95 & 30,52 & $10.795,00$ & $6.074,00^{* *}$ \\
\hline estcapPL & 38,92 & 39,19 & 40,46 & $10.294,00^{* *}$ & $4.202,00^{* *}$ \\
\hline DvLEBITDA & 6,34 & 5,87 & 7,95 & $6.332,00$ & $3.154,00^{* *}$ \\
\hline DiCPDivTotal & 21,05 & 21,28 & 26,24 & $8.206,00$ & $4.407,00^{* *}$ \\
\hline ExAT & 61,78 & 60,50 & 60,17 & $10.065,00$ & $6.579,00^{* *}$ \\
\hline ExPL & 135,99 & 133,44 & 134,49 & $9.597,00$ & $6.858,00^{* *}$ \\
\hline ExRec & 445,06 & 406,84 & 499,07 & $11.897,00$ & $3.123,00^{* *}$ \\
\hline AfixoPL & 34,64 & 34,87 & 33,59 & $8.940,00$ & $8.369,00$ \\
\hline InvestPL & 0,10 & 0,13 & 0,14 & $2.521,00$ & $2.435,00$ \\
\hline LG & 0,88 & 0,90 & 0,89 & $8.153,00$ & $10.256,00$ \\
\hline LC & 1,66 & 1,61 & 1,70 & $9.127,00$ & $9.991,00$ \\
\hline LS & 1,32 & 1,35 & 1,31 & $8.775,00$ & $10.170,00$ \\
\hline CapiGir & $424.000,00$ & $450.300,00$ & $541.433,00$ & $9.262,00$ & $9.434,00$ \\
\hline CapEmp & $4.076 .305,00$ & $4.305 .363,00$ & $4.439 .212,00$ & $7.049,00^{* *}$ & $2.777,00^{* *}$ \\
\hline PME & 20,96 & 25,25 & 29,16 & $7.099,00^{* *}$ & $1.859,00^{* *}$ \\
\hline PMP & 43,55 & 41,90 & 45,49 & $9.208,00$ & $5.314,00^{* *}$ \\
\hline PMR & 54,46 & 55,54 & 59,05 & $10.611,00^{*}$ & $2.752,00^{* *}$ \\
\hline CF & 35,21 & 34,32 & 42,07 & $10.855,00^{* *}$ & $3.925,00^{* *}$ \\
\hline $\mathrm{CO}$ & 87,98 & 83,90 & 94,61 & $11.063,00^{* *}$ & $2.649,00^{* *}$ \\
\hline EBITDA_ & $165.412,00$ & $141.659,50$ & $100.194,50$ & $6.780,00$ & $11.068,00^{* *}$ \\
\hline LAIR_DFL & $93.093,00$ & $82.462,50$ & $53.604,00$ & $8.436,00$ & $12.638,00^{* *}$ \\
\hline $\mathrm{GA}$ & 0,13 & 0,14 & 0,12 & $6.764,00$ & $15.701,00^{* *}$ \\
\hline GPL & 0,33 & 0,31 & 0,28 & $7.540,00^{*}$ & $13.412,00^{* *}$ \\
\hline MEBIT & 14,48 & 14,29 & 10,65 & $9.197,00$ & $12.026,00^{* *}$ \\
\hline $\mathrm{ML}$ & 7,87 & 9,94 & 3,84 & $6.852,00^{* *}$ & $13.950,00^{* *}$ \\
\hline MEBTIDA & 20,90 & 20,96 & 16,59 & $7.648,00$ & $10.177,00^{*}$ \\
\hline ROA & 1,06 & 1,27 & 0,43 & $6.899,00^{* *}$ & $14.538,00^{* *}$ \\
\hline ROIC & 1,95 & 1,84 & 1,17 & $8.710,00$ & $12.209,00^{* *}$ \\
\hline InvesCap & $3.274 .480,00$ & $3.368 .236,00$ & $3.581 .083,00$ & $8.979,00$ & $3.495,00^{* *}$ \\
\hline $\mathrm{AF}$ & 1,60 & 1,73 & 1,37 & $8.000,00$ & $11.429,00^{* *}$ \\
\hline AOp & 1,70 & 1,81 & 1,79 & $8.112,00$ & $9.006,00$ \\
\hline $\operatorname{Rec}$ & $563.106,00$ & $553.400,00$ & $502.550,00$ & $4.746,00^{* *}$ & $14.991,00^{* *}$ \\
\hline
\end{tabular}

Notas: ${ }^{*}$ Significativo a menos de $5,0 \% ;^{* *}$ Significativo a menos de $1,0 \%$.

Fonte: elaborada pelos autores (2020).

Ademais, verificou-se uma queda sistemática de todos os indicadores econômicofinanceiros ligados à rentabilidade das empresas. Independentemente da forma de se calcular o resultado da empresa (EBIT, EBITDA, ML), ou da base de mensuração (ROA, ROIC), verificamse reduções significativas. Tal situação pode ser relacionada à queda da demanda já abordada e aos custos fixos e aqueles com perfil sticky, tal como apresentado por Anderson, Banker e Janakiraman (2003). Tal verificação ratifica a $\mathrm{H} 2 \mathrm{~b}$.

Considerando a dependência de recursos para financiamento das operações e a queda da rentabilidade, esperar-se-ia um aumento dos níveis de endividamento das empresas, uma vez que seria necessário o financiamento externo para suprir a falta de recursos, tal como desenvolvido com base em Padoveze e Benedicto (2014). Essa situação foi observada no caso 
da maior parte dos indicadores econômico-financeiros de estrutura de capital analisados (DivTtLq, DivTtBruta, div_brAtivo, divbPL, estcapPL, DvLEBITDA, DiCPDivTotal, ExPL, ExRec e InvestPL). Verificou-se um aumento de quase todos os indicadores relacionados à estrutura de capital, independentemente da base usada para mensuração (ativo total, receita líquida ou patrimônio líquido). Tal situação pode ser explicada pela grande obtenção de recursos das empresas, tal como relatado na subseção anterior. Salienta-se a queda do indicador AfixoPL, que pode ser associada à queda de investimentos em ativos fixos por parte das empresas. Tal verificação ratifica a $\mathrm{H} 2 \mathrm{c}$.

Por fim, apenas os indicadores econômico-financeiros relacionados à liquidez (LG, LC, LS e CapiGir) não apresentaram variações significativas, com valores bem próximos ao do período anterior. $\mathrm{O}$ aumento do ciclo operacional implica em um aumento do ativo das empresas, enquanto a redução do ciclo financeiro gera o mesmo efeito no passivo. Ademais, as vultuosas obtenções de empréstimos também influenciam ambos os elementos patrimoniais, o que explicaria a sua não variação de forma significativa, tal como explicam Gelbcke et al. (2018.) O único indicador desse grupo com variação significativa seria o capital empregado (CapEmp) que, basicamente, refere-se à soma entre o patrimônio líquido e a dívida onerosa da empresa. Nesse caso, o aumento observado pode ser associado à aquisição de empréstimos. Assim, não é possível ratificar $\mathrm{H} 2 \mathrm{~d}$.

\subsection{COVID-19 E A BUSCA POR EMPRÉSTIMOS E FINANCIAMENTOS}

Nesta subseção, apresentam-se os resultados do modelo estimado para análise da busca de empréstimos e financiamentos das empresas da amostra. Tal como apresentado na subseção anterior e ratificado em $\mathrm{H} 2 \mathrm{c}$, houve um aumento substancial do volume de endividamento das empresas no período da pandemia. Salienta-se que, para o desenvolvimento do modelo, foram retiradas as observações referentes às seguintes empresas e que foram identificadas como outliers: Intermedica, Eternit, AES Tiete E, Coelce, CPFL Renovav, Ceb, Ceee-D, Cemig, Rede Energia. Tal procedimento foi necessário para garantir o atendimento aos pressupostos da técnica multivariada empregada, quais sejam: homoscedasticidade e ausência de autocorrelação (HAIR JR. et al., 2009).

A Tabela 5 apresenta as estatísticas do modelo estimado. Salienta-se que o mesmo apresentou um valor de $\mathrm{R}^{2}$ ajustado de $84,2 \%$ (demonstrando uma boa capacidade de explicação do fenômeno), assim como um fator de inflação da variância (variance inflation fator - VIF) de apenas 1,463, indicando a ausência de multicolinearidade entre as variáveis selecionadas para o modelo conforme (HAIR JR. et al., 2009). Por sua vez, o teste F demonstrou a significância do modelo como um todo e os testes de Durbin-Watson e ShapiroWilk demonstraram a ausência de autocorrelação entre os resíduos e a homoscedasticidade dos mesmos de acordo com os parâmetros dos mesmos autores.

Com base nos resultados da Tabela 5, verificou-se que o porte da empresa (TAM) está positiva e significativamente relacionado à maior obtenção de recursos por parte da empresa neste período. Tal resultado corrobora o exposto por autores como Frank e Goyal (2009), que enfatizam que empresas maiores são mais diversificadas e têm uma melhor reputação junto ao mercado credor, assim como menores níveis de assimetria informacional quando buscam recursos junto a terceiros. Assim, ratifica-se a H3a. Verificou-se, ainda, que a variável escudo fiscal não proveniente de dívida (EFNPD) apresentou uma relação positiva e significativamente relacionada à maior obtenção de recursos por parte da empresa. Porém, tal situação não seria esperada com base em autores como Titman e Wessels (1988), uma vez que não haveria maiores incentivos tributários. Uma explicação para tal fenômeno observado se refere à 
Efeitos da pandemia de COVID-19 sobre a sustentabilidade econômico-financeira de empresas brasileiras

necessidade de se levantar recursos no momento de incerteza provocado pela pandemia, sendo que empresas com maiores volumes de ativos fixos (especialmente imobilizado) tiveram mais facilidade para fazê-lo em detrimento das demais. Dessa forma, não é possível ratificar H3f.

Tabela 5 - Estatísticas do modelo de regressão sobre a aquisição de empréstimos e financiamentos

\begin{tabular}{ccccc}
\hline Variável & Coeficiente & Erro-padrão & $\mathbf{t}$ & p-valor \\
\hline Intercepto & $-3,86$ & 1,16 & $-3,33$ & 0,00 \\
TAM & $1,03^{* * *}$ & 0,06 & 15,89 & 0,00 \\
CRES & 0,28 & 0,34 & 0,83 & 0,41 \\
LUC & $-1,02$ & 1,55 & $-0,66$ & 0,51 \\
TANG & $1,15^{*}$ & 0,62 & 1,84 & 0,07 \\
SING & 0,56 & 0,82 & 0,68 & 0,50 \\
EFNPD & $13,84^{* * *}$ & 4,36 & 3,18 & 0,00 \\
RISC & $-0,02^{* *}$ & 0,01 & $-2,45$ & 0,02 \\
\hline Testes & Coeficiente & $\mathbf{p}$-valor & & \\
Teste F & $61,9^{* * *}$ & 0,00 & & \\
Durbin-Watson & 2,23 & 0,34 & & \\
Shapiro-Wilk & 0,98 & 0,20 & & \\
\hline
\end{tabular}

Notas: ${ }^{*}$ Significativo a menos de $10,0 \% ;{ }^{* *}$ Significativo a menos de $5,0 \% ;{ }^{* * *}$ Significativo a menos de $1,0 \%$.

Fonte: elaborada pelos autores (2020).

Ainda considerando a Tabela 5, verificou-se que o maior nível de risco das empresas (RISC) implicou em um menor volume de capital de terceiros obtidos pelas empresas no período. Tal observação está de acordo com o esperado com base em autores como Perobelli e Fama (2002) e Fama e French (2005), uma vez que o maior nível de risco das empresas implicaria em uma maior dificuldade em obter crédito, ratificando H3g. Por fim, o maior nível de tangibilidade da empresa (TANG) também implicou em um maior nível de obtenção de recursos durante o primeiro trimestre de 2020 (coeficiente significativo a menos de 10,0\%). Tal achado pode ser explicado, com base em Rajan e Zingales (1995), uma vez que o ativo tangível serve de garantia, há uma redução do custo de agência relacionado à dívida sob a perspectiva do credor. Ratifica-se, assim, $\mathrm{H} 3 \mathrm{~d}$.

Por fim, as variáveis, taxa de crescimento (CRESC), lucratividade (LUC), e singularidade (SING) não apresentaram coeficientes significativos com o maior volume de captação de recursos no primeiro trimestre de 2020, não sendo possível ratificar, respectivamente, as hipóteses $\mathrm{H} 3 b, \mathrm{H} 3 \mathrm{c}$ e H3e. Sobre as duas primeiras variáveis, é importante destacar que há fortes discussões teóricas sobre o real efeito das mesmas sobre o endividamento das empresas, sendo que a pecking order theory prevê sinais diametralmente opostos à trade-off theory (empregada como base para este trabalho) (FAMA; FRENCH, 2005; FRANK; GOYAL, 2009). No que se refere à variável SING, é relevante enfatizar que ela foi mensurada a partir do volume de ativos intangíveis da empresa, sendo que autores como Perobelli e Famá (2002) indicam outras proxies consideradas mais adequadas sua mensuração. Porém, as mesmas não estavam disponíveis aos pesquisadores na Plataforma Economática ${ }^{\circledR}$. Além disso, é importante destacar que tais variáveis usualmente foram propostas e testadas em ambientes relativamente estáveis, sendo que os efeitos da pandemia de COVID-19 no mercado de crédito também podem ter afetado a significância de tais variáveis no curto prazo.

\section{CONSIDERAÇÕES FINAIS}

A pesquisa desenvolvida visou analisar os efeitos da pandemia de COVID-19 sobre a sustentabilidade econômico-financeira de empresas brasileiras de capital aberto. Para tanto, 
desenvolveu-se uma pesquisa quantitativa e descritiva, com base em dados trimestrais das empresas, assim como suas notas explicativas do primeiro trimestre de 2020 (período de início da pandemia no Brasil). Com base no estudo, constatou-se uma forte da pandemia de COVID19 sobre a sustentabilidade econômico-financeira das empresas estudadas. As ações tomadas pelos governos de diferentes esferas a partir de março, especialmente o isolamento social, assim como a incerteza de diversos agentes econômicos sobre a duração e outros aspectos da pandemia, resultaram em fortes perdas de valor no mercado de capitais, deterioração nos diversos indicadores econômico-financeiros das empresas e a alta significativa de captação de recursos de terceiros no período.

Verificou-se o efeito da pandemia de COVID-19 no valor de mercado das empresas estudadas no mês de março de 2020, com perdas de mais de $\mathrm{R} \$ 800$ bilhões. Tal perda, porém, não foi homogênea entre os setores nem entre as empresas. No total, as empresas reportaram 400 efeitos da pandemia sobre suas operações, sendo os principais: a incerteza nas previsões, a queda da demanda e a inadimplência. Esperava-se, com base na HEM (FAMA, $1970 ; 1991)$, que empresas com maiores perdas no mercado fossem as que mais reportassem efeitos negativos da pandemia sobre suas operações, porém, tal hipótese não foi suportada pelos dados analisados. Para lidar com os efeitos nocivos da pandemia sobre suas operações, as empresas reportaram 864 medidas de mitigação, sendo as principais: o reporte periódico ao mercado, a segurança dos funcionários e algumas relacionadas à gestão econômicofinanceira. Ressalta-se que o reporte de mais que o dobro do número de medidas de mitigação em relação a efeitos da pandemia pode ser relacionado à tentativa de demonstrar a proatividade de sua gestão aos stakeholders de forma a minimizar as perdas no mercado.

Para uma análise mais holística do desempenho econômico-financeiro das empresas, foram realizadas análises de variações entre o terceiro e o quarto trimestre de 2019 e, entre este e o primeiro trimestre de 2020 (período de evolução da pandemia). Observou-se uma queda significativa das receitas das empresas neste último período em relação ao anterior, tal como esperado pelas medidas de mitigação da pandemia, conforme (SALISU E VO, 2020). Assim como esperado, com base nas hipóteses da pesquisa, observaram-se significativos aumentos dos indicadores econômico-financeiros ligados aos ciclos financeiros e operacional das empresas, assim como daqueles relacionados ao endividamento delas. Por outro lado, verificou-se uma redução dos indicadores relacionados à rentabilidade, o que pode ser explicado pela redução das receitas, assim como a alavancagem operacional e o comportamento assimétrico dos custos dessas organizações, como enfatizam (GOLDEN et al., 2019).

Diante do cenário de queda significativa de receitas, verificou-se um aumento significativo no volume de captação de empréstimos e financiamentos por parte das empresas no primeiro trimestre de 2020 . Verificou-se, porém, que tal aumento nesse volume pode ser estreitamente relacionado a variáveis determinantes de estrutura de capital clássicas, enfatizadas por autores como Titman e Wessels (1988), Rajan e Zingales (1995) e Perobelli e Fama (2002), quais sejam: tamanho (porte), tangibilidade, escudo fiscal não proveniente de dívidas e risco. Entretanto, ao contrário do esperado, não foram obtidas evidências da relação entre essa captação extra de recursos no período e as variáveis taxa de crescimento, lucratividade e singularidade.

Salienta-se que o estudo ora apresentado apresentou algumas limitações, quais sejam: (a) enfatizou-se apenas o primeiro trimestre de 2020 (início da pandemia no país), pois ainda não há dados disponíveis para outros períodos; (b) não foi possível fazer uma relação direta entre o desempenho econômico-financeiro das empresas e os efeitos e medidas de mitigação 
da pandemia; e (c) o foco em notas explicativas podem levar a vieses diante da divulgação (ou não) de informações consideradas estratégicas por parte das empresas. Como pesquisas futuras, sugere-se o acompanhamento longitudinal dos efeitos da pandemia e das medidas tomadas pelas empresas para mitigá-los, assim como as consequências econômicofinanceiras de tais ações. Ademais, seria importante analisar o papel de subsídios e incentivos governamentais às empresas no combate aos efeitos nocivos da pandemia sobre as operações das empresas. Por fim, recomenda-se a comparação da sustentabilidade econômicofinanceira das empresas considerando os diferentes níveis de controle da pandemia por país (curva de casos e mortes, $R_{0}$, tempo de quarentena etc.).

\section{REFERÊNCIAS}

ASHRAF, B. N. Economic impact of government actions to control COVID-19 pandemic: Evidence from financial markets. 2020. Disponível em: https://papers.ssrn.com/sol3/papers.cfm?abstract_id=3628693. Acesso em: 30 jun. 2020.

ANDERSON, M. C.; BANKER, R. D.; JANAKIRAMAN, Surya N. Are selling, general, and administrative costs "sticky"? Journal of Accounting Research, Chicago, v. 41, n. 1, p. 47-63, jan./mar., 2003. DOI: https://doi.org/10.1111/1475-679X.00095.

ANDEKINA, R.; RAKHMETOVA, R. Financial analysis and diagnostics of the company. Procedia Economics and Finance, Amsterdã, v. 5, p. 50-57, jan./abr., 2013. DOI: https://doi.org/10.1016/S2212-5671(13)00008-7.

BANCO CENTRAL DO BRASIL. Focus: Relatório de Mercado: Expectativas de Mercado. 2020. Disponível em: https://www.bcb.gov.br/content/focus/focus/R20200515.pdf. Acesso em: 15 jul. 2020.

BARDIN, L. Análise de Conteúdo. São Paulo: Edições 70, 2016.

BRASIL, BOLSA BALCÃO - B3 Ações. 2020. Disponível em: http://www.b3.com.br/pt_br/produtos-e-servicos/negociacao/renda-variavel/empresaslistadas.htm Acesso em: 30 jun. 2020.

BRASIL. Emenda Constitucional n. 106 de 7 de maio de 2020. 2020a. Institui regime extraordinário fiscal, financeiro e de contratações para enfrentamento de calamidade pública nacional decorrente de pandemia. Disponível em:

http://www.planalto.gov.br/ccivil_03/constituicao/Emendas/Emc/emc106.htm. Acesso em: 15 jul. 2020.

BRASIL. Lei n. 14.020, de 6 de julho de 2020. 2020b. Institui o Programa Emergencial de Manutenção do Emprego e da Renda; dispõe sobre medidas complementares para enfrentamento do estado de calamidade pública reconhecido pelo Decreto Legislativo no 6, de 20 de março de 2020, e da emergência de saúde pública de importância internacional decorrente do coronavírus, de que trata a Lei no 13.979, de 6 de fevereiro de 2020; altera as Leis nos 8.213, de 24 de julho de 1991, 10.101, de 19 de dezembro de 2000, 12.546, de 14 de dezembro de 2011, 10.865, de 30 de abril de 2004, e 8.177, de 10 de março de 1991; e dá 
outras providências. Disponível em: http://www.planalto.gov.br/ccivil_03/_ato20192022/2020/lei/L14020.htm. Acesso em: 15 jul. 2020.

BRASIL. Decreto no $\mathbf{1 0 . 3 5 0}$ de 18 de maio de 2020. 2020c. Dispõe sobre a criação da Conta destinada ao setor elétrico para enfrentamento do estado de calamidade pública reconhecido pelo Decreto Legislativo no 6, de 20 de março de 2020 e regulamenta a Medida Provisória no 950, de 8 de abril de 2020, e dá outras providências. Disponível em: http://www.planalto.gov.br/ccivil_03/_ato2019-2022/2020/decreto/D10350.htm. Acesso em: 15 jul. 2020.

COMITÊ DE PRONUNCIAMENTOS CONTÁBEIS - CPC. CPC 00 (R2) - Estrutura Conceitual para Relatório Financeiro, dez. 2019. Disponível em:

http://static.cpc.aatb.com.br/Documentos/573_CPCO0(R2).pdf. Acesso em: 30 jun. 2020.

DE LIMA TAVARES, A.; SILVA, C. A. T. A análise financeira fundamentalista na previsão de melhores e piores alternativas de investimento. Revista Universo Contábil, Blumenau, v. 8, n. 1, p. 37-52, jan./mar., 2012. DOI: https://doi:10.4270/ruc.2012103.

FAMA, E. F. Efficient capital markets: A review of theory and empirical work. The Journal of Finance, Filadélfia, v. 25, n. 2, p. 383-417, 1970. DOI: https://doi.org/10.2307/2325486.

FAMA, E. F. Efficient capital markets: II. The Journal of Finance, Filadélfia, v. 46, n. 5, p. 15751617, dez. 1991. DOI: https://doi.org/10.1111/j.1540-6261.1991.tb04636.x.

FAMA, E. F.; FRENCH, K. R. Financing decisions: who issues stock? Journal of Financial Economics, [s.I.], v. 76, n. 3, p. 549-582, maio/jun., 2005. DOI: https://doi.org/10.1016/j.jfineco.2004.10.003.

FERNANDES, F.; FERREIRA, M. E.; RODRIGUES, E. R. Análise de rentabilidade utilizando o Modelo Dupont: estudo de caso em uma operadora de planos de saúde. Revista de Gestão em Sistemas de Saúde, São Paulo, v. 3, n. 2, p. 30-44, jul./dez. 2014. DOI: http://dx.doi.org/10.5585/rgss.v3i2.97.

FERNANDES, N. Economic effects of coronavirus outbreak (COVID-19) on the world economy. 2020. Disponível em: https://papers.ssrn.com/sol3/papers.cfm?abstract_id=3557504. Acesso em: 30 jun. 2020.

FERGUSON, N. et al. Report 9: Impact of non-pharmaceutical interventions (NPIs) to reduce COVID19 mortality and healthcare demand. 2020. Disponível em:

<https://www.imperial.ac.uk/media/imperial-college/medicine/sph/ide/gidafellowships/Imperial-College-COVID19-NPI-modelling-16-03-2020.pdf >. Acesso em: 30 jun. 2020.

FRANK, M. Z.; GOYAL, V. K. Capital structure decisions: which factors are reliably important? Financial Management, Tampa, v. 38, n. 1, p. 1-37, jan./mar. 2009. DOI: https://doi.org/10.1111/j.1755. 
FUNDO MONETÁRIO INTERNACIONAL - FMI. World Economic Outlook Update. A crisis like no other, an uncertain recovery. 2020. Disponível em:

https://www.imf.org/en/Publications/WEO/Issues/2020/06/24/WEOUpdateJune2020. Acesso em: 15 jul. 2020.

GELBCKE, E. R.; SANTOS, A.; IUDÍCIBUS, S.; MARTINS, E. Manual de contabilidade societária: aplicável a todas as sociedades de acordo com as normas internacionais e do CPC. 3 ed. São Paulo: Atlas, 2018.

GOLDEN, J.; MASHRUWALA, R.; PEVZNER, M. Labor adjustment costs and asymmetric cost behavior: An extension. Management Accounting Research, [s.I.], v. 46, p. 100647, mar. 2020. DOI: https://doi.org/10.1016/j.mar.2019.07.004.

HAIR JR., J. F. et al. Análise multivariada de dados. Porto Alegre: Bookman, 2009.

HASSAN, T. A. et al. Firm-level exposure to epidemic diseases: Covid-19, SARS, and H1N1. 2020. Disponível em: https://www.nber.org/papers/w26971. Acesso em: 30 jun. 2020.

HEYDEN, K. J.; HEYDEN, T. Market reactions to the arrival and containment of COVID-19: an event study. 2020. Disponível em:

https://papers.ssrn.com/sol3/papers.cfm?abstract_id=3587497. Acesso em: 30 jun. 2020.

JOHNS HOPKINS UNIVERSITY. Covid-19 Map-Johns Hopkins Coronavirus Resource Center. 2020. Disponível em: https://coronavirus.jhu.edu/map.html. Acesso em: 15 jul. 2020.

LEE, P. T.; LIN, C.; SHIN, S. A comparative study on financial positions of shipping companies in Taiwan and Korea using entropy and grey relation analysis. Expert Systems with Applications, [s.I.], v. 39, n. 5, p. 5649-5657, 2012. DOI: https://doi.org/10.1016/j.eswa.2011.11.052.

MANN, P. S. Introdução à estatística. 5 ed. Rio de Janeiro: LTC, 2007.

MAROCO, J. Análise estatística com utilização do SPSS. Lisboa: Sílabo p. 822. 2010.

NICOLETA-CORNELIA, B. S. et al. Accounting and extra-accounting information-valences in meeting the financial analysis. Procedia-Social and Behavioral Sciences, v. 62, p. 531-535, 2012. DOI: https://doi.org/10.1016/j.sbspro.2012.09.087.

PADOVEZE, C. L.; BENEDICTO, G. C. Análise das demonstrações financeiras. São Paulo: Cengage Learning, 2014.

PEROBELLI, F. F. C.; FAMÁ, R. Determinantes da estrutura de capital: aplicação a empresas de capital aberto brasileiras. Revista de Administração da Universidade de São Paulo, São Paulo, v. 37, n. 3, p. 33-46, 2002. Disponível em:

http://www.spell.org.br/documentos/ver/16659/determinantes-da-estrutura-de-capital-aplicacao-a-empresas-de-capital-aberto-brasileiras/i/pt-br. Acesso em: 15 jul. 2020. 
RAJAN, R. G.; ZINGALES, Luigi. What do we know about capital structure? Some evidence from international data. The Journal of Finance, Filadélfia, v. 50, n. 5, p. 1421-1460, 1995. DOI: https://doi.org/10.1111/j.1540-6261.1995.tb05184.x.

ROSS, S. A. et al. Administração financeira. Porto Alegre: AMGH, 2015.

SALISU, A. A.; VO, X. V. Predicting stock returns in the presence of COVID-19 pandemic: The role of health news. International Review of Financial Analysis, v. 71, p. 101-546, 2020. DOI: https://doi.org/10.1016/j.irfa.2020.101546.

SAMPIERI, R. H.; COLLADO, C. H. \& LUCIO, P. B. Metodologia de pesquisa. 3 ed. São Paulo: MacGraw-Hill,2006.

SILVA, J. Análise financeira das empresas. 12. ed. São Paulo: Atlas, 2013.

TITMAN, S; WESSELS, R. The determinants of capital structure choice. The Journal of Finance, Filadélfia, v. 43, n. 1, p. 1-19, 1988. DOI: https://doi.org/10.1111/j.15406261.1988.tb02585.x. 